\title{
An Approach to the Commercial Production of Highly Active Pharmaceutical Ingredients
}

\author{
Andreas Beyeler*, Roland Wilhelm, and Bernd Brodbeck
}

\begin{abstract}
To meet the requirements for production of highly active pharmaceutical ingredients (API) new approaches and technical solutions are required. Prior to the design and construction of a new multipurpose manufacturing facility, a process study was performed to clarify the future needs. During the planning phase, concepts were defined and elaborated to meet production, cleaning, health and safety standards. The ideas were taken into account and a small-scale manufacturing facility was designed and realized accordingly.
\end{abstract}

Keywords: API · Highly Active Compounds · Manufacturing $\cdot$ Multipurpose plant $\cdot$ Pharmaceuticals

\section{Introduction}

Many new drug applications cover a very specific area of a disease and are highly efficient in small amounts. In addition, personalized health care frequently targets small populations in order to apply a drug beneficially and specifically. This has a direct impact on the manufacturing processes of these drugs. In the past most of the active ingredients were produced on a multi-ton scale. In future there will be a shift towards the production of smaller volumes but also a shift to more sophisticated technology to handle highly active compounds with an Occupational Exposure Level (OEL) below $1 \mu \mathrm{g} / \mathrm{m}^{3}$ (for a definition see section 2 ) safely.

To meet these requirements, a process study was started with five APIs of the latestage portfolio from the development area which represented potential candidates for future commercial manufacturing. The chosen candidates required low demands on API according to forecasts and some of the intermediates and products have been classified as highly active compounds. The study was the starting point for the design and layout of a future multipurpose chemical manufacturing facility to meet the anticipated additional needs for the next decade.

\section{Occupational Hygiene and Health}

The employer is legally obliged to ensure that workers are not overexposed to any of the substances present at their workplaces. The borderline between acceptable and unacceptable exposure is called Occupational Exposure Level (OEL). Within Roche there is a company directive regarding Occupational Hygiene and Health stating that the prevention of occupational (over)exposure shall be ensured primarily by collective protection measures (technical measures, engineering controls) and not by the provision of personal protective equipment.

Personal protective equipment (PPE) is not acceptable as primary means of controlling worker exposure if feasible technical or organizational solutions exist (Fig. 1 ). On the other hand, PPE is acceptable as a safety measure in case of upset conditions or upon non routine or unplanned activities.

\section{Process Study}

The scope of the process study was to gather the most important facts and key messages regarding the design of a multipurpose plant for manufacturing the selected as well as other future highly active APIs with an OEL down to $50 \mathrm{ng} / \mathrm{m}^{3}$. Additionally, the latest available technology has been considered in order to meet current and future industrial occupational hygiene standards. The results from the study have been used to define the layout of the production facility, to specify the main technologies and equipment, to choose the right materials of construction and to determine the required infrastructure.

\subsection{Assumptions and Scope of the Process Study}

The process study was done with five different APIs out of the portfolio derived from development. Considering the isolated intermediates, a total of 18 chemical steps or physical transformations were investigated. All investigated steps were planned to be produced in house. The production volumes were taken from estimated demands for a defined year of production (2018). The range of API supply varied from less than $100 \mathrm{~kg}$ up to $500 \mathrm{~kg}$ per year. For each step a process flow for a commercial production was established. Based on these datasets, batch times, cycle times and capacities were determined. The facility is planned to operate in a 24/7 schedule over the whole year.

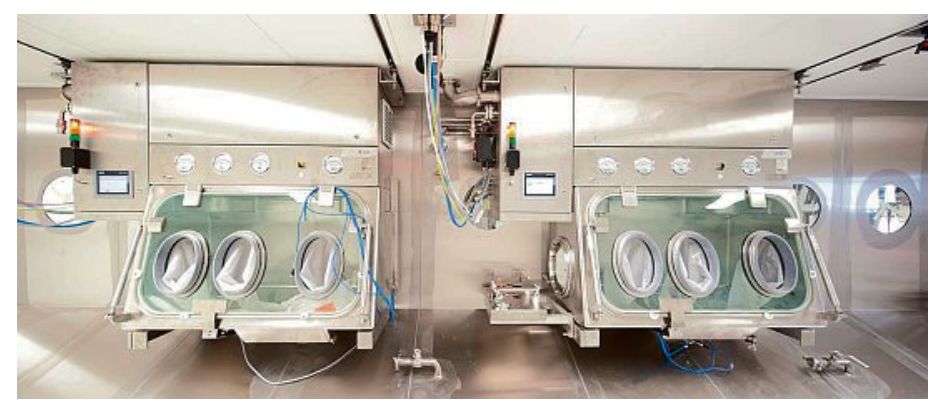
reactors in a dedicated room. 
A smaller production facility for highly active compounds with an OEL of $50 \mathrm{ng} /$ $\mathrm{m}^{3}$ was already running for several years within the development area. This train was an ideal basis for the design of the new manufacturing facility. The design of both manufacturing facilities for highly active compounds has been based, amongst others, on the Roche Plant 2000 concept. ${ }^{[1]}$ According to the Plant 2000 concept, a chemical manufacturing train consists of three standard chemical reactors, each with a heating/cooling system and the ability for distillation, as well as a separating unit and a dryer (Fig. 2). Due to occupational hygiene aspects automated and manual handling of solids should be avoided whenever a technical solution can be applied. Therefore, a filter dryer instead of a centrifuge combined with a standard dryer was chosen in order to provide separating and drying steps within one unit.

Since product demands are rather small, the number of batches will be small, too. Therefore, the impact for longer cycle times due to the combined equipment of filtration and drying is looked at having only a minor influence on the duration of a campaign.

\subsection{Capacity Estimation}

Three different equipment sizes of reactors were investigated: $400 \mathrm{~L}, 630 \mathrm{~L}$ and $1000 \mathrm{~L}$. For the analysis of the plant capacity, it was assumed that changeover and cleaning will take the same amount of time for all investigated equipment sizes since piping and installation would be almost identical. For calibration and maintenance 14 days per year were taken into account. For a changeover within the same product 7 days were assumed. For a change over in between two APIs (OEL $\geq 1 \mu \mathrm{g} / \mathrm{m}^{3}$ ) 15 days and for a changeover in between APIs (OEL $50 \mathrm{ng}$ to $1 \mu \mathrm{g} / \mathrm{m}^{3}$ ) 22 days were considered. Assuming the 18 steps will be produced within one year, changeover and cleaning will take as long as 180 days per year. This highlights the importance of an optimized cleaning design for the manufacturing facility, as discussed in section 9 .

Based on these assumptions, only 1000 $\mathrm{L}$ reactor capacity was large enough to cover the predefined needs. Compared to a $400 \mathrm{~L}$ train a capacity increase of $26 \%$ and compared to a $630 \mathrm{~L}$ train a capacity increase of $14 \%$ could be shown. The capacity increase seems to be quite small compared to the data shown in Table 1. However, half of the time throughout a production year has to be used for changeover and cleaning.

It could be shown that a $1000 \mathrm{~L}$ train covers best the range between demands of 50 to $500 \mathrm{~kg}$ per campaign. In addition, it makes sense to reduce the number of batches per product to a reasonable mini-

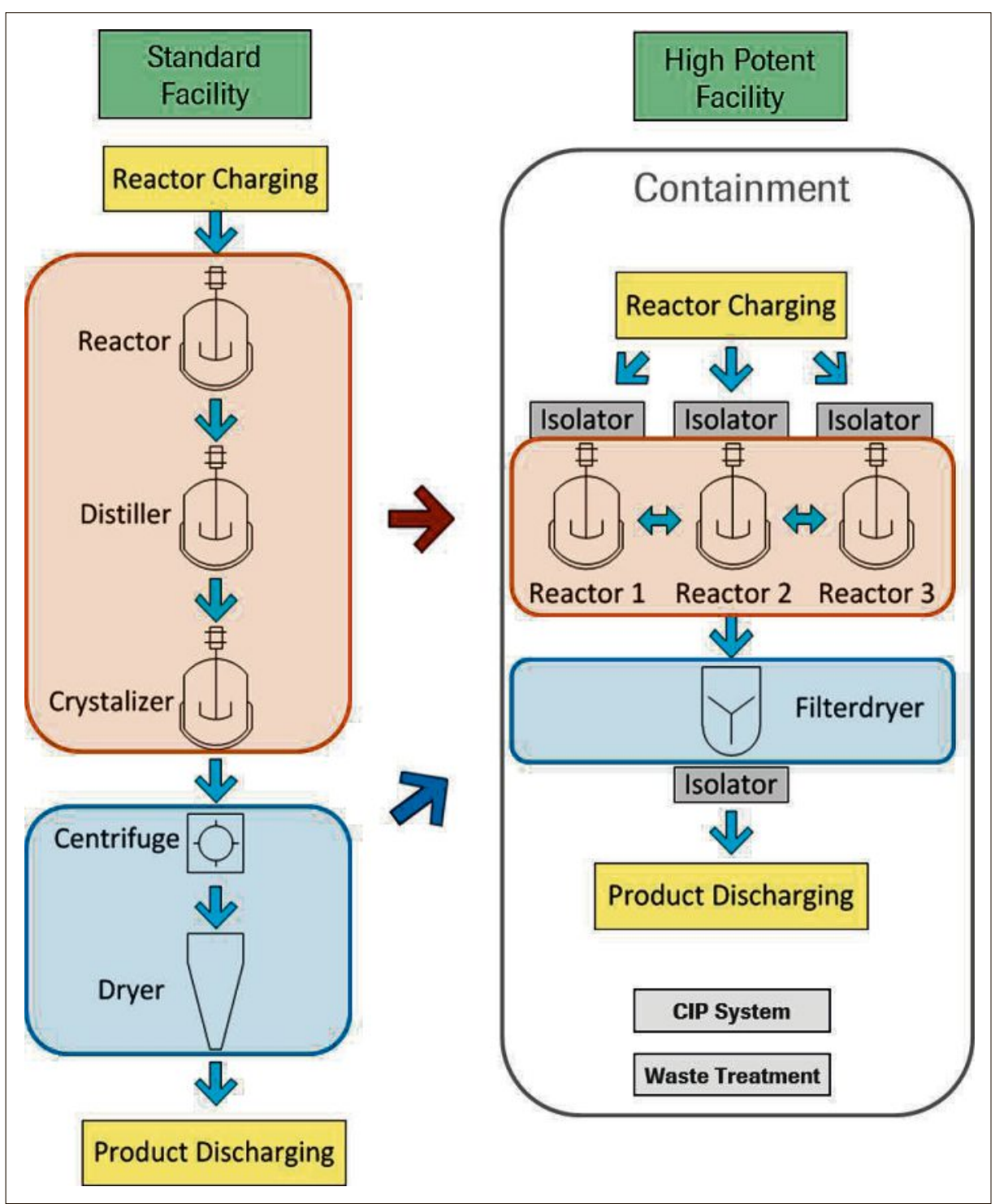

Fig. 2. Difference between the Plant 2000 concept (left) and the concept for the high potent facility (right).

Table 1. Number of production batches needed per campaign.

\begin{tabular}{c|c|c|c|}
\hline Batches per step & $400 \mathrm{~L}$ train & $630 \mathrm{~L}$ train & $1000 \mathrm{~L}$ train \\
\hline Smallest campaign & 4 & 3 & 2 \\
\hline Largest campaign & 58 & 34 & 19 \\
\hline All 18 steps together & 279 & 177 & 105
\end{tabular}

mum in order to minimize time consuming and more complicated manual handling steps, both for cycle time and labour intense process steps. Preparation and cleaning efforts for these steps remain almost the same regardless of the batch size.

\subsection{Process Conditions and Equipment Flexibility}

According to the Plant 2000 concept, all three reactors are equipped with a heating/cooling system serving a temperature range from $-20^{\circ} \mathrm{C}$ to $+160^{\circ} \mathrm{C}$. Additionally, each reactor has been equipped with a distillation device. This already covers the requirements for most production steps. During the process study, only one step required additional low temperature cooling to about $-100{ }^{\circ} \mathrm{C}$, therefore one reactor has been foreseen to be equipped with a special cooling device for low temperature cooling. All reactors could be used for a pressure up to 6 bar, but during normal operation they are limited to 2 bar.

From the 18 production steps investigated during the process study, only three required reaction conditions applying pressure, one of them up to 30 bar during a hydrogenation reaction. A reactor of $1000 \mathrm{~L}$ at a pressure of more than 30 bar 
in combination with hydrogen reactions requires additional safety measures and special kind of equipment. As a result, a dedicated hydrogenation reactor located in a separate containment, which can be connected to the multipurpose manufacturing facility, was included in the planning.

At least half of the investigated production steps need distillation during the work up, one step even needs two in parallel. Some of the distillations are running with vacuum down to 40 mbar abs. This is already covered within the standard equipment setup.

12 out of 18 investigated process steps require at least one filtration step with filter aid. For this purpose single-use cartridges will be used. Ideally a contained system for the safe change of the filter cartridges should be installed.

Beside the investigated reaction steps taken as a basis for the process study, the manufacturing facility should be flexible to cover a wide spectrum of reaction conditions.

As a result, all reactors and individual process units of the train can be deliberately configured for each production step. As a precondition, the manufacturing facility has to work automated with a process control system completely on a recipe-driven basis. The recipe consists of a modular setup per process unit on a Siemens PCS7 platform.

Working volumes range from 200 to $1000 \mathrm{~L}$ per reaction. Distillation end points are at least at $100 \mathrm{~L}$. For production steps which require a very low reactor volume, one smaller reactor was taken into consideration. However, after a detailed evaluation, this scenario has not been followed up. Regarding the minimum stirring vol- ume between a $630 \mathrm{~L}$ and a $1000 \mathrm{~L}$ reactor there is no significant difference due to a very similar equipment design.

Furthermore, smaller reactor size limits flexibility for the setup at the upper end of the filling level. Consequently the batch size would be smaller too, resulting in an increased number of batches and a prolongation of the campaign.

It has been defined that equipment installation has to be in corrosion-resistant materials. Consequently, two reactors are glass-lined steel and one reactor is made out of Hastelloy. The filter dryer was made out of Hastelloy since in glass-lined steel installations it would be difficult to clean due to gaps at connection points. As a consequence, various glass-lined steel parts would need to be dismantled and cleaned separately. Regarding occupational hygiene aspects this would be an additional risk and, moreover, the risk of damage due to dismantling activities is increased as well.

In order to complete the desired plant setup, a contained filter station within an isolator, two dosing vessels, a small mobile slurry vessel, two mobile liquid phase tanks, an off-gas scrubber and three vacuum pumps have been added.

\subsection{Potential Capacity Expansion}

In case of upcoming constraints, the feasibility of an extension of the manufacturing facility was evaluated. Taking an additional filter dryer into account as well as a fourth reactor, the capacity of the plant could be almost doubled due to at least partial parallelization of the processes in various scenarios. Additional installation of only one piece of equipment, second filter dryer or fourth reactor, does not have such a significant impact. However, a second filter dryer would result in a capacity increase of about $30 \%$. Therefore, extension of the manufacturing facility has been taken into account during the design phases of the project, for a potential ramp up in the future.

\subsection{Powder Handling}

All assessed process steps have an intermediate which is solid. Considering the extended API portfolio, only very few intermediates are liquids or solutions. Thus, powder handling is a key task for producing highly active compounds. Usually, the activity of a compound increases the closer it gets to the final structure of the API. In chemical synthesis the isolated product is reintroduced as raw material in the following step. Dispensing of the intermediate in the required amounts for the next process step directly upon unloading of the dried material is highly preferable since additional manual handling can be minimized. However, this might not always be feasible since for example also seeding portions may be needed.

Several different solids will be charged during a process step, therefore dispensing of solid material prior to loading it into a reactor is important. According to the process study, amounts of highly active material vary between $100 \mathrm{~kg}$ and 100 grams (seeding crystals) per batch.

As a consequence of the Roche standards for occupational health (see section 2), isolator technology was chosen to cover solid handling activities of highly active substances in a closed manner (Fig. 3). Only in exceptional cases is open solid handling acceptable within dedicated areas.

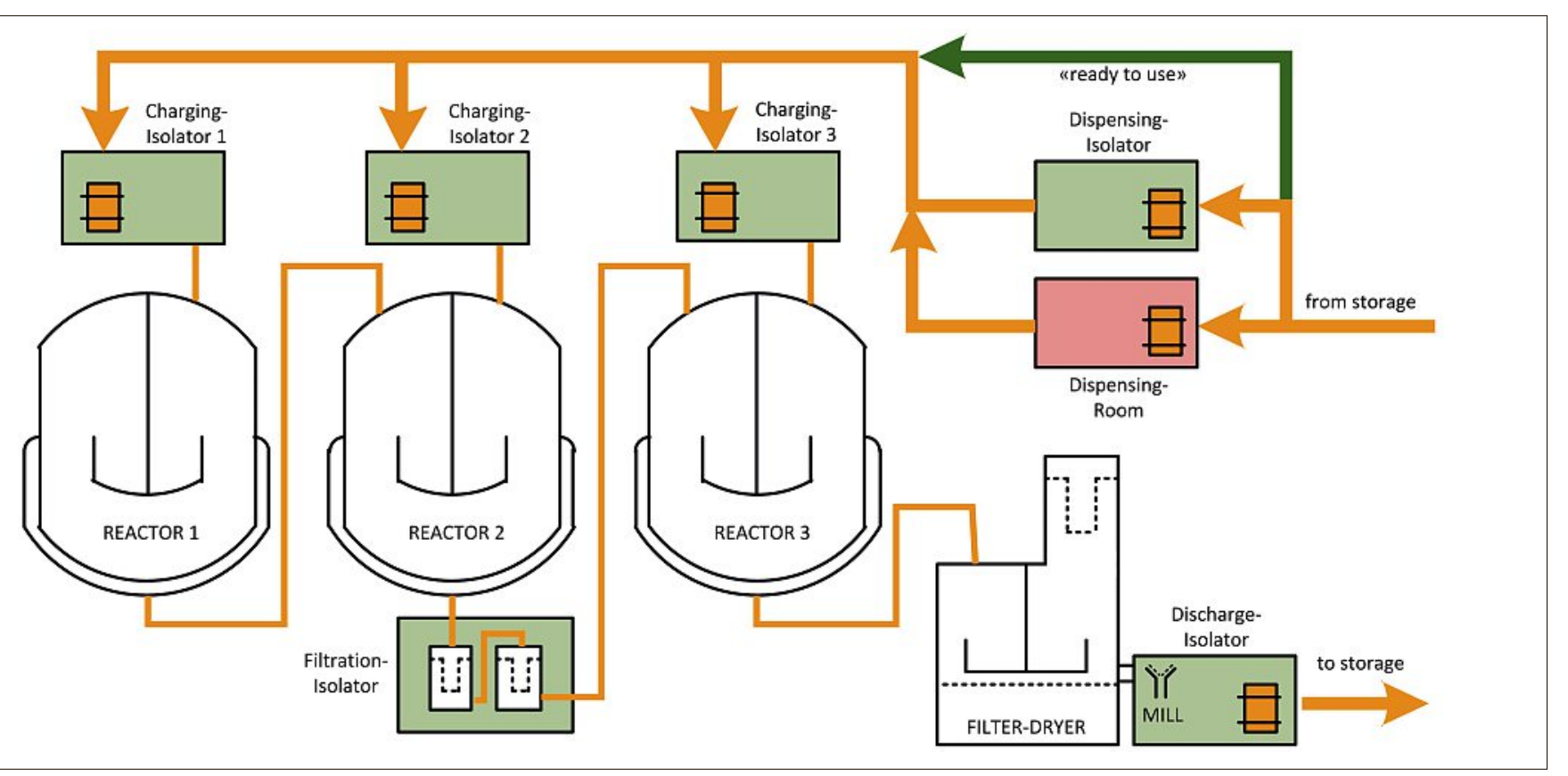

Fig. 3. Principal setup of the high potent facility with process flow of solid material. 
Charging solids to the reactors will be performed without additional weighing. The same approach could be used for the interface between chemical and galenical production. Primary and secondary packaging as well as transportation has to be adapted to the requirements. Often there is resampling, dispensing and repacking of the produced API, which is complicated and time consuming. To enhance efficiency, common procedures are important in order to simplify material handling for all involved parties.

\subsection{Other General Aspects}

Beside technical aspects there are a lot more topics that are impacted by the production of highly active compounds.

First of all, individual knowledge and correct handling of the complex devices is important. Full commitment, understanding and training of the complex manual handling steps are essential to meet the industrial hygiene standards. Handling and working in this environment has to be strictly standardized and continuously trained to achieve and in particular to maintain extremely high working and hygienic standards. Also the non-routine tasks like behavior in the case of emergency or spill have to be looked at and refreshed on a regular basis.

Cleaning will be one of the core businesses during operation of the manufacturing facility due to the expected frequent product changes and also due to extremely low acceptance limits for changeovers (see section 9).

Primary and secondary packaging as well as transportation has to be adapted to the requirements. For instance resampling of material on stock is often a complicated or time consuming procedure.

Manual handling steps should be minimized and combined if reasonably possible. An example is the combination of the last chemical and the last crystallization step. Therefore, a second filter dryer is of benefit. In the first filter dryer the crude API could be isolated, if necessary even dried, then re-dissolved in the desired solvent, sent to another reactor for crystallization and isolated within the second filter dryer. For these operations an isolator for unloading solids would not even be necessary. One key requirement for the last crystallization step of API manufacturing is usually an accurate API concentration and solvent ratio. Using in-line NIR, IR or $\mathrm{UV} / \mathrm{vis}$ probes the exact concentration and composition of the solution can be accurately measured and also adjusted in order to meet the precise requirements for the final crystallization. This would also open up the opportunity to develop and file new processes accordingly.

If the annual demand of an API is very low, a single campaign will deliver product for several years. This can be a reasonable advantage, despite the costs of material on stock. It is a valuable option since for such small campaigns setup and cleaning takes longer than the production slot itself, so additional material can be made with essentially almost only additional raw material costs. At the same time adequate stability programs for APIs and intermediates will have to be setup right from the beginning.

\section{Project Approach and Project Setup}

In order to meet the targets of a schedule driven project, a systematic and transparent project management approach was applied in compliance with the Roche Engineering Manual in the Pharmaceuticals Division.

Planning and execution of the project was divided into phases. Each phase had defined activities, deliverables and a dedicated organizational structure. The individual phases had been linked by decision steps (milestones) in order to review and evaluate critical project activities and deliverables to ensure consistency with project objectives and business requirements prior the next phase commenced.

Phasing project design and execution systematically reduced project risks and avoided reproduction from one phase to another.

The milestone approach (project execution sequence) reflected the course of the complete project (Fig. 4). The content of each phase had been defined in individual process descriptions. All required deliverables were available at each milestone to give assurance that the project has met the goal of the appropriate phase and is ready to move forward.

At the beginning project initiation was done thoroughly to ensure that the project is aligned with the business strategy and needs, that economic value is identified before major funds and resources had been dedicated. Also project scope, timing and location had been defined and approved prior to the start of major design work.

During project initiation other companies that had already built a plant for highly active compounds were visited and their approach was discussed with both engineering and users.

Main equipment and the basic layout was defined during the project initiation phase and strictly followed until handover of the production facility to the user.

Project objectives had been defined from the basis for the elaboration of the user requirements and of project execution strategies. The objectives had been prioritized to align decisions with importance of project specific properties.

The objectives had been reviewed and re-confirmed regularly to continuously ensure adherence to them.

User requirements had been defined at beginning of the project in line with the business needs of Roche and compliant with applicable regulations (e.g. GMP, SHE, Roche Directives).

Project design reviews, cost reviews, safety reviews and risk reviews had been conducted at the end of each project phase to ensure adherence to project objectives, the user requirements and the principles defined in the Roche Engineering Manual.

Project organization was set-up with a Roche project manager, a Roche project management team, design and construction contractors as well as internal and external consultants. In parallel, the future user was part of the project team represented by a user team lead including user team and owner representatives. The project manager and the user team lead reported to a steering committee during the complete duration of the project.

\section{Setup of the Plant}

\subsection{Basic Setup}

The manufacturing facility has been realized in an existing chemical production building with four full floors (ground floor, $1^{\text {st }}, 2^{\text {nd }}$ and $3^{\text {rd }}$ floor). The floor height is more than $5 \mathrm{~m}$, therefore, intermediate floors have been installed when needed. The manufacturing facility has been extended across all floors in order to place the relevant equipment and provide sufficient space for the required process operation.

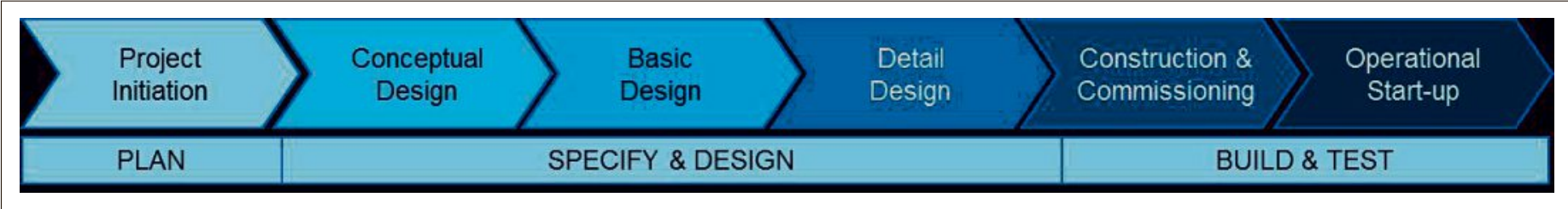

Fig. 4. Different phases of the project (milestone approach). 
Moreover, there was space available on top of the building and within the basement.

A schematic setup of the plant is shown in Table 2.

The $3^{\text {rd }}$ floor has been used for process support functions. Equipment for process support involves three vacuum pump systems, two $400 \mathrm{~L}$ dosing units and an offgas scrubber. One $400 \mathrm{~L}$ dosing unit has been realized in glass-lined steel, the other one in Hastelloy. Additionally, a 1000 L 40 bar hydrogenation reactor has been located on the $3^{\text {rd }}$ floor within a dedicated compartment equipped with a dedicated HVAC system. The high pressure reactor can be used as stand-alone unit, completely independent from the rest of the manufacturing facility, or in combination with the manufacturing facility as an integrated system.

On the second floor the three $1000 \mathrm{~L}$ reactors have been located next to each other within a dedicated room. This is different from a standard manufacturing facility that places reactors in vertical orientation to each other. Due to advantages regarding industrial hygiene aspects and to realize short transfer lines, the $1000 \mathrm{~L}$ reactors have been positioned horizontally next to each other. In order to provide transfers from one reactor to another reactor, pressure/vacuum needs to be applied. Transfer pumps for process mixtures have been avoided. In exceptional cases, a mobile transfer pump can be utilized.

A solid wall ending right on the surface of the three reactors splits the space into two independent rooms. On one side there is the charging room. In this room no other flange of the reactor ends other than the man lid. This man lid ends in a charging isolator (Fig. 1). For the three reactors two isolators have been installed which can be configured at the beginning of a campaign if needed. Also a mobile slurry container is placed there, which can be filled in a closed manner from the open dispensing room which has been designed next to the charging room. Otherwise there is neither equipment nor piping in the charging room. In case of a spill outside the isolator caused by a containment break, only this room is contaminated and it is easy to clean since it is literally empty and designed as a clean room. All piping and instrumentation is on the opposite side of the wall in the process room. This is where the operators usually supervise the process. The process room stretches over four floors (1, 1.5, 2 and 2.5) and is connected via an internal staircase enabling short paths within the containment for the principal working areas.

On the 2.5 floor of the process room just above the reactors there are tantalum condensers for the glass-lined equipment and a Hastelloy condensor for the Hastelloy reactor and next to them the distillate receivers, one for each reactor. Also on this floor there is a jumper station where dosing unit and rising pipes are connected for the desired setup for a campaign.

On the 1.5 floor there are all reactor outlets as well as a filtration isolator and the upper part of the filter dryer. The filter dryer can be configured to any of the reactors. In contrast to the process study the filter dryer was chosen in a slightly smaller scale (400 L volume, $0.4 \mathrm{~m}^{2}$ filter surface) principally because a high filter surface is not favorable for small amounts of isolated material. Furthermore, the isolation step can easily be made by refilling the filter dryer in several portions rather than to make a complete transfer prior to the filtration. Most of the actual products have a dilution factor above 10 in the final step, so there is little risk that the filter dryer will be the bottleneck concerning batch size. As for the filtration isolator (Fig. 5) there are two Hastelloy polishing filters and a combined filter. This filter is designed as a 12 inch cartridge filter but can also be used as a bag filter, depending on the requirement. All of them are insulated and can be electrically preheated as necessary.

On the first floor there are mobile liquid phase tanks e.g. for the extraction phase and the mother liquor tank. Opposite to this room directly below the charging room there is the discharging room, designed as a clean room, easy to clean and basically empty apart from the lower part of the filter dryer and the directly connected double chamber isolator. This isolator has an integrated rotating sieve mill for delumping the product. Finally, on the ground floor there is more infrastructure like the CIP-System (see section 9.3.1), a solvent waste collector (4000 L) and the blow-down tank.

\subsection{Additional Functions}

A general thought to future installation showed a huge difference between standard manufacturing facilities and a contained facility. In a standard facility additional equipment can be easily put alongside the existing equipment. This will not be possible for the production of highly active compounds because they will be outside the secondary containment protecting the environment. Therefore, an additional room called test field was taken into the containment. In this room different operations could be performed. So for example a milling isolator, a small-scale preparative HPLC equipment or a special distillation or separation unit could be installed. The

Table 2. Schematic setup of the plant

\begin{tabular}{|c|c|}
\hline Floor & Main Process \\
\hline 3 & $\begin{array}{c}\text { Dosing, } \\
\text { Hydrogenation }\end{array}$ \\
\hline 2.5 & Distillation \\
\hline 2 & $\begin{array}{l}\text { Charging, } \\
\text { Reaction }\end{array}$ \\
\hline 1.5 & Filtration \\
\hline 1 & $\begin{array}{l}\text { Isolation, } \\
\text { Drying, } \\
\text { Packaging }\end{array}$ \\
\hline
\end{tabular}

0

Cleaning

\section{Main Equipment}

Dosing Vessels, Hydrogenation Reactor

Vapor Condensers,

Distillate Receivers

Reactors

Filter Isolator

Filter Dryer with Isolator, Mother Liquor Tank, Mobile Tanks

CIP System, Solvent Waste Tank

Support
Process/Equipment
Vacuum,
Off-gas Scrubber
Configuration Panel
Dispensing
(open \& isolator)
Washing Area
(manual \& washing
machine)

Blow Down Tank Test Field

\section{Infrastructure \\ Control Room \\ User Offices \\ Automation Rooms \\ Automation Rooms}

\section{HVAC}

Storage Rooms

Central Heating/

Cooling System 


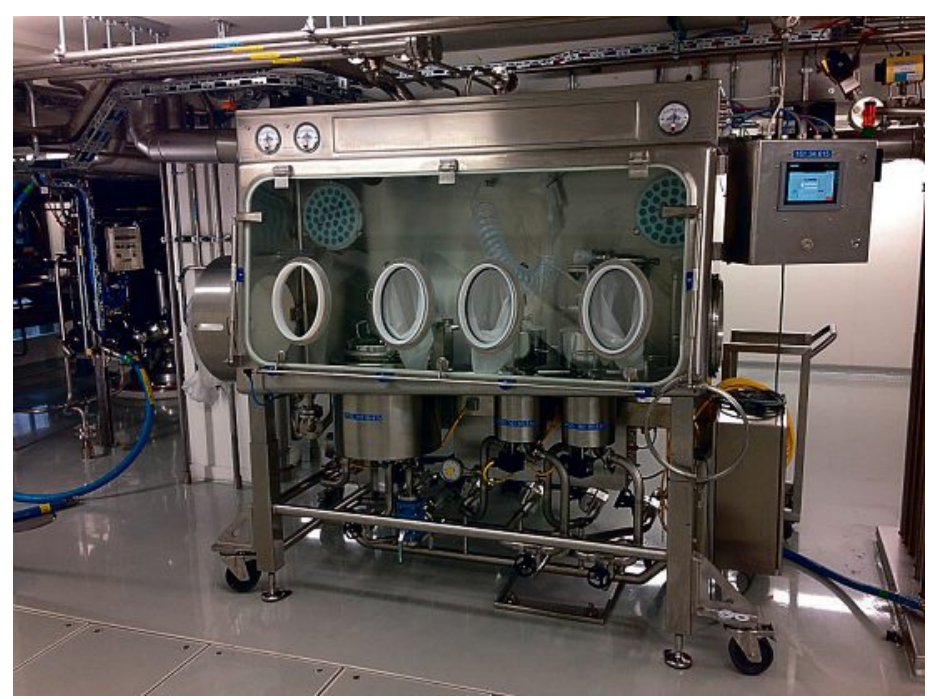

Fig. 5. Filter isolator with a combined filter (left) and two polishing filters (right).
Hastelloy reactor and the Hastelloy dosing unit can be upgraded with an additional cooling circuit allowing process temperatures down to $-100^{\circ} \mathrm{C}$. Both of them are already equipped with a gas inlet function and piping from outside the building.

Also a decanting unit could be added in the distillation line. Out of construction constraints the optional column on top of a reactor was omitted. If a rectification is necessary there is space with the free height of $5 \mathrm{~m}$ available in the test field.

Whenever possible, process analytical technology (PAT) should be applied for in-process controls to minimize classical in-process control samples. To avoid that all equipment needs to be explosion proof, outside the containment a PAT room has been realized in a non explosion proof area with the possibility to draw fiber optics or light conductors to this area.

\section{Containment Philosophy}

The major difference to a standard production facility used in the production of API is the fact that it has to be fully contained in order to protect the environment in case of an airborne or liquid spill. Therefore a house-in-house concept within the existing production building was chosen. All handling of highly active components happens within this containment, for example dispensing of material, cleaning of small parts or decontamination of broken parts of equipment. Also additional equipment should be placed within this containment if needed. An important point for the personnel is the transparency within the containment (Fig. 6). Whenever possible and reasonable, large windows were installed to lighten up the inside and give a good overview to the operators what is happening in adjacent rooms.

Applying company standards consistently for occupational health means there is no need for special working clothes or additional personal protective equipment (PPE). So there is no need for a central changing room and operators have access to the containment from every main floor. For vertical transportation of chemicals and goods the existing infrastructure outside the containment can be used.

During discussions with occupational hygiene representatives it was agreed that there is a principal difference inbetween a powder release and a liquid spill. The contaminated area of liquid spills can easily be limited to a specific area. Therefore decontamination and cleaning is much easier since the highly active compound is not airborne dust, but in solution or suspension. On the other hand an accidental powder release means that the whole room has to be quarantined and only released after thorough and efficient cleaning has been performed which needs to be confirmed by occupational hygiene measurements.

Within the containment there are several different segregated rooms with dedicated room pressure. On each main floor there is an airlock for entrance to the containment. This airlock is both material and personnel entrance to the containment and is operated in overpressure to work as a pressure barrier for airborne particles. The room pressures decreases from the entrance airlock towards the process rooms in the containment. The lowest room pressure is where open product handling is performed (open dispensing, manual cleaning). The containment has an airlock control system to ensure the room pressure is in the right range before opening the next door. From all the major working areas there is a direct access to a decontamination area with shower and a changing room. So in case of a spill only a small area is contaminated and has to be quarantined, whereas the rest of the containment remains unaffected. All emergency exits are directly linked to a central alarm system, so any breakage of the main containment will immediately be detected.

\section{Material Flow/Material Handling}

Three different solvents can be configured for a campaign directly from the tank farm going to each main apparatus. Alternatively, liquid mixtures or solvents can be delivered to the desired equipment inside the containment via a dosing station outside on the third floor. This simplifies handling of big mobile units.

As already mentioned, solids will be charged to the reactors from an isolator. Therefore all materials have to be packed in RTP containers (RTP: Rapid Transfer Port) which can be connected to all isolators within the manufacturing facility to introduce materials and tools. All solid raw materials are brought into the containment in their original packaging. There is a dispensing isolator for highly active compounds in a dedicated room where the material is packed into adequate sized bags with the desired amount (Fig. 7). Alternatively, the material can also be dropped into a slurry container directly connected to the isolator. This container can then be transferred into the process room where the slurry is charged into a reactor.

The dispensing isolator has been designed in a way that most commercially available drums can be handled. If extra sizes or designs are delivered, the inliners will have to be repacked at the warehouse into more standardized drums. Solid material which is not highly hazardous can also be dispensed in an open dispensing room inside the containment in plastic bags and RTP drums. In addition the mobile

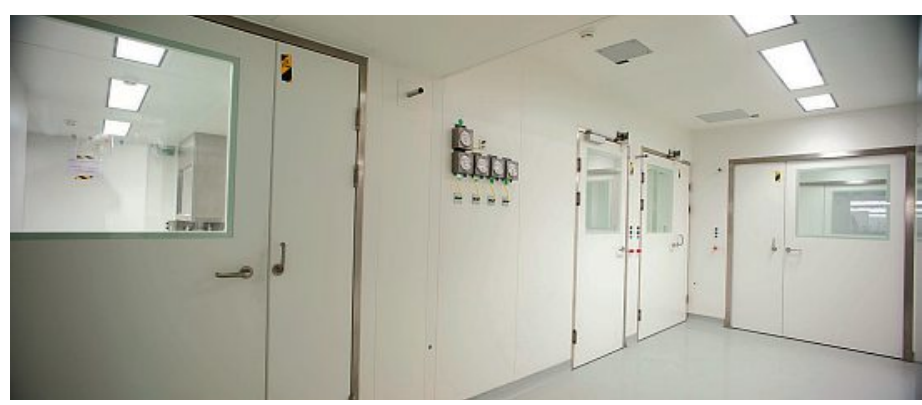

Fig. 6. View inside the corridor in the containment leading to the dispensing and process area. 


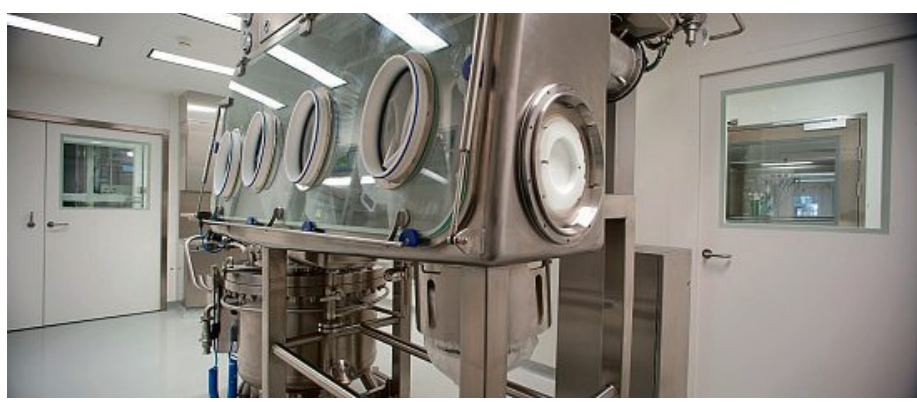

Fig. 7. Room with the dispensing isolator including a slurry container and the RTP-Port. A separate drum adapter is installed in the back of the isolator. slurry container mentioned above could be charged via a charging desk in the wall without contamination. This is possible because the slurry container is in the charging room directly connected to the lower side of the desk in the open dispensing room next to it. So a contamination coming from the open dispensing room and being carried outside by the mobile vessel can be completely avoided.

Very small amounts as seeding crystals or catalysts might be added directly into the reactors through a small diameter double valve system, or as a suspension also via the sampling unit.

According to the principal difference between liquid solutions or suspension and solid material, the sampling devices on the reactors are commonly used devices without special safety measures.

The sampling unit of the filter dryer however is contained via a single-use bag with gloves for handling.

During the technical batches the drying process should be fixed based on physical parameters showing the end point of the drying operation. For this reason a function for determining the differential uptake of condensate in small quantities in the condensation collection unit has been installed.

Filter dryer discharging of the desired intermediate/API will be performed in a double chamber isolator directly linked to the filter dryer. In the first chamber the filter dryer is unloaded and the material is sieved via a sieve mill and dropped directly in an endless liner which is attached to the ceiling of the lower chamber. In the lower chamber the bag is weighed, sealed and packed into a second endless liner at the bag out port, and packed into the desired drum. According to experience only with a double chamber system and the double endless liner system can exposure limits down to $50 \mathrm{ng} / \mathrm{m}^{3}$ be assured. The pack size should not exceed the size and the maximum allowed weight for an RTP drum in order not to require additional dispensing for the next process step.

Solid waste, cleaning material or contaminated filters from the isolators will be taken out via RTP or by the bag out port posal. and disposed in a dedicated drum for dis-
Liquid waste streams from the production or cleaning process can be gathered in the solvent waste collector vessel located on the ground floor, then after specific treatment, if necessary, sent to the collective waste plant for external incineration. Isolator washing liquids can be directed to the same vessel.

In case of breakdown of a piece of equipment it has to be disconnected after a first flush from the fixed plant and packed into plastic bags. Then it can be brought to the open washing area where a plant operator in full personal protection equipment will clean and decontaminate the equipment. Quite often during such operations cleaning and further disassembling has to be done stepwise. After cleaning of the area the repairs can be performed directly in place without taking the material piece out of the containment.

\section{Infrastructure}

\subsection{Heating/Cooling System}

In order to provide heating and cooling energy for the production facility, a dedicated central heating/cooling system has been designed and installed. Specific heat transfer oil provides temperatures from -20 to $160{ }^{\circ} \mathrm{C}$ for the various consumers by utilizing primary energies as steam, cooling water and brine (Fig. 8).
To cover the temperature range, three independent heating/cooling loops $\left(-20^{\circ} \mathrm{C}\right.$, $+20^{\circ} \mathrm{C},+160{ }^{\circ} \mathrm{C}$ ) have been routed next to the consumers to tie-in in dedicated secondary loops at the specific equipment. According to the temperature specification, the secondary loop draws the relevant amount of heat transfer oil from the heating/cooling loops in order to provide the requested temperature level (Fig. 9).

\subsection{Off-gas Treatment}

Off-gas is routed to an incineration system. For neutralization purposes a dedicated off-gas scrubber located inside the secondary containment of the production facility can be utilized prior sending the off-gas to the incinerator. The off-gas system has been realized to be part of the cleaning concept and can be back-washed.

\section{Cleaning}

\subsection{Experience}

Cleaning of multipurpose equipment for product changeover is very challenging. Due to highly active API and small batch sizes, the maximal allowable carry over (MACO) from the previous API production to the next one ranges from $0.1 \mathrm{~g}$ to $1.0 \mathrm{~g}$ for the entire equipment of this manufacturing facility. To reliably achieve these low limits, a sophisticated cleaning concept, easily cleanable equipment and knowledge about hard to clean areas is needed.

Since cleaning of a complex production facility may take several days and sometimes a few weeks, depending on the acceptance limit, minimizing cleaning time is highly desired and in the focus of the plant manager. In production of highly active API the usually rather small production campaigns and low cleaning limits

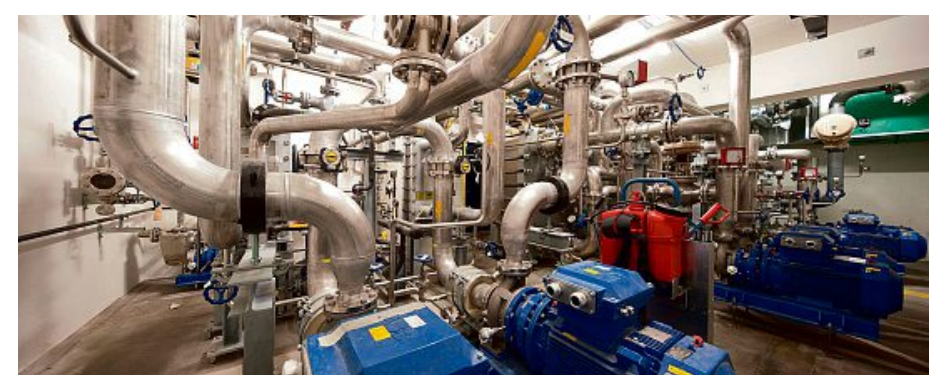

Fig. 8. Central heating/cooling system in the basement.

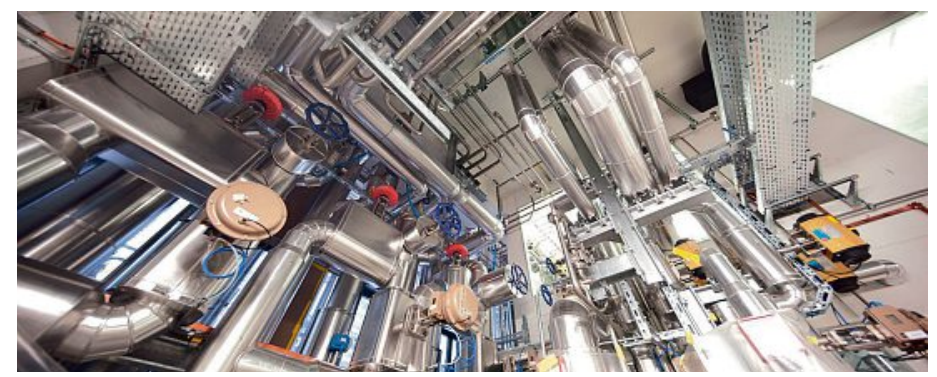

Fig. 9. Infrastructure installation has been routed outside the containment. 
worsen the balance between cleaning and production time. This fact increases the pressure for thoroughly thinking about opportunities to optimize commonly established ways of cleaning and challenges design and construction of a production facility.

\subsection{Technical Improvements}

An avoidance strategy is the key principle for easily cleanable equipment and installation. What is not installed does not have to be cleaned. This sounds very simple but realization is not always an easy task as during production activities, a facility with many options to run chemical processes in an ideal setup is desired. Moreover, it is important to take samples at all phases of a chemical synthesis step. Therefore, requirements from various stakeholders have been challenged and real requirements for an efficient production were identified.

Standard production equipment shows significant disadvantages regarding cleanability, e.g.:

- Type and number off sealing surfaces and flanges

- Poor drainability of equipment and piping

- Complex collectors and distributors at in- and outlets of equipment

- High number of lines and branches

- Instruments and valves not in latest hygienic design

- Headspace not completely wettable

- Poor cleanability of vacuum and offgas lines

- Cleaning media cannot be preheated

- Roughness and huge welding seams in equipment and piping

- Many hard to clean parts which require disassembling and manual cleaning

- Independent cleaning of different vessels not possible due to connecting transfer lines and missing possibility for direct solvent waste disposal

Several measures for better cleanability of the manufacturing facility have been designed and implemented, e.g.:

- A new corrosion-resistant pipe class has been set up in offset-free, hygienic design

- Visual inspection of welding seams in piping and equipment has been done prior to installation

- Dead spaces of valves have been minimized by using membrane valves or segment ball valves

- Direct 1:1 configuration instead of collectors and distributors for process fluids (e.g. two bottom outlet valves for each reactor) is possible

- Number of lines has been limited to the minimum requirement

- Easily cleanable reactors with flat lids to eliminate long nozzles and low surface roughness
- Clean-in-place (CIP) system (CIP media supply)

- CIP media supply via static and rotating nozzles, static lances, spray rings for all equipment

- Vertical vapor condenser equipped with CIP connection

- Spray coverage testing of containers and vessels has been done at the vendor workshop and in place after installation

- Cleanable vacuum and off-gas lines

- Charging solids to reactors via pressure surge protected lid has been designed no additional valve needed

- Independent cleaning of different sections is possible, due to a solvent waste collector system and CIP-nodes between two sections for cleaning of transfer lines.

\subsection{Cleaning Concept}

In pharmaceutical production cleaning processes have to be validated. For multipurpose units a viable option is validation based on the solubility of the previous product and the acceptance limit for the residual contamination and the maximal allowable carryover, respectively.

To ensure a good solubility the cleaning media is usually an organic solvent like methanol or a mixture of solvents.

\subsubsection{Cleaning of the Production Facility}

Regarding cleaning, the production facility has been separated into different sections which can be cleaned independently. This provides the opportunity to parallelize cleaning of several sections and individualize cleaning to the type and degree of contamination of the various sections.

Cleaning of the production facility is divided into the following steps:

- Preliminary cleaning including manual cleaning of hard to clean areas of each section

- Fine cleaning of the individual sections including sampling (rinse)

- Final rinse of connected sections including sampling (rinse and swab)

- Visual checks with endoscope and vessel-camera

A dedicated CIP vessel has been installed for the supply of the manufacturing facility with CIP media. Preheated solvent can be supplied to each section via circulation pump and media loop, with different pressure levels depending on the location and type of the CIP device of the receiver. The CIP system is operated with $100 \%$ fresh solvent to avoid contamination of the entire system. Due to the fact that the reactors have not been equipped with a transfer pump, recirculation of CIP media within a section is not possible. Since the reactors have been designed according to good cleanability of the head space and less complex distributers have been installed, recirculation is not necessary for cleaning purposes.

\subsubsection{Cleaning of Other Equipment}

There is equipment which is not cleaned via the CIP System.

- Isolators are cleaned with a spray gun and wiped down manually since this is easy to perform and automation is not an advantage as it needs much manual support.

- Different small parts from the process equipment, isolators and tools will be washed in a washing machine available within the containment.

- Room cleaning is performed manually.

\subsection{Cleaning-friendly Production}

Another part of the avoidance strategy is to prevent equipment from heavy soiling while production is running. If equipment does not get as dirty and there is a lower potential of building up deposits or even crusts, then cleaning will be more efficient and much faster.

With relatively few batches and a short overall production time per step, deposits and crusts are less likely to build up and most probably they will not be as hard to remove. Nevertheless, there are also additional measures during the production. For example, the solvent addition is routed through the condenser into the reactor after a solid charging step. This way the dust is already washed down before it has the chance to stick or being carried forward by aerosols at the beginning of the distillation. Flushing of transfer lines with a few liters of solvent after the reaction mixture has passed is another simple preventive measure to avoid slowly accumulating deposits.

Flushing the equipment with process solvent after the last batch of a campaign also helps to bring the ideal solvent in the specific vessel. If the API is not stable, a decontamination rinse is obviously the preferred option.

\section{Acknowledgements}

The authors would like to acknowledge all the contributions from many motivated people to this project, which started in 2013 and is handed over to the user in 2016. Many ideas arose, were challenged, planned, realized and tested with a lot of enthusiasm and commitment over the whole period, from the process study to the handover. The core team would like to thank numerous companies for their openness to show their current production facilities for highly active compounds as well as for the fruitful exchange of ideas and knowledge.

Received: June 3, 2016

[1] M. Born, R. Fretz, R. Miess, T. Oxley, Chimia 2000, 54, 724 